\title{
A Musical Lens on Spatial Representations of Form to Support Designers and Teachers Using Hybrid Learning Spaces
}

\section{Stephanie Wilson ${ }^{1}$ (D)}

Accepted: 2 October 2021 / Published online: 25 October 2021

(c) Crown 2021

\begin{abstract}
Explorations of the potential of hybrid learning spaces have been accelerated by the rapid transition to online learning caused by the Covid-19 pandemic. Educational spaces that accommodate hybrid learning may be seen as more complex spaces to navigate, particularly as the number of potential social and spatial arrangements available to the teacher tends to multiply. This creates a greater need to represent the overarching structure of a learning and teaching session, particularly as some students are colocated and others are remote in time and place. To explore ways of supporting educational practitioners and designers in managing the increasing number of permutations available to them in hybrid learning spaces, this paper turns to musical forms for inspiration. These forms, and the way they are represented diagrammatically, are examined to support thinking around how the sequence of, and interaction between, educational parameters across time may be represented. A discussion of the relationship between temporal and spatial representations of musical form is also used to support a broader notion of space in education, one that may be useful as physical and networked environments become less clear-cut. By exploring how the form of a learning session might be best represented to show the relationship of the parts to the whole in a single image, this paper contributes to the areas of hybridity and learning space design and use.
\end{abstract}

Keywords Musical form - Spatial representations · Hybrid learning spaces · Educational structures

\section{Introduction}

Explorations of the potential of hybrid learning spaces have been accelerated by the rapid transition to online learning caused by the Covid-19 pandemic, particularly when universities found themselves in a situation where a proportion of

Stephanie Wilson

stephanie.wilson@sydney.edu.au

1 The University of Sydney Business School, The University of Sydney, Sydney, Australia 
their students were able to return to campus, and the remainder were not. In this paper, the term hybrid learning refers to learning that occurs in classes where oncampus and off-campus students are participating in the same learning session synchronously. As suggested by Fawns (2019), this does not mean that students in the classroom are learning purely 'face-to-face' and students learning remotely are 'online', as digital technology also permeates the classroom and students learning remotely are not separate from situated, socio-material activity (133). As a result, educational spaces that accommodate hybrid learning may be seen as more complex spaces to navigate, particularly as the number of potential social and spatial arrangements available to the teacher tends to multiply. This creates a greater need to represent the overarching structure of a learning and teaching session, particularly as some students are co-located and others are remote in time and place. Drawing on design patterns for hybrid learning, these representations may indicate, for example, points in a learning session when real-time data is fed back in to support learning, moments where digital activities are translated into the physical world and vice versa, and points at which artefacts can move through spaces (Köppe, Nørgård, and Pedersen 2017; Mor, Dimitriadis, and Köppe 2020).

To explore ways of supporting educational practitioners and designers in managing the increasing number of permutations available to them in hybrid learning spaces, this paper begins by turning to musical forms for inspiration. In Western tonal music, form is primarily concerned with the order of melodic, harmonic and rhythmic events. The arrangement of instruments or the way a piece is orchestrated may also determine the formal structure of a work. This paper considers the evolution of spatial representations of form in music. When thinking about how music is represented visually, most people would think of musical notation (also known as the musical score). Musical notation is used to represent in full what we hear when we listen to a piece of music. Representations of musical form however, are not designed to capture every note. Instead, they are visual representations of the broader structures of the music caused by repeated, varied or contrasting melodies, harmonies, rhythms or other elements. That is, they communicate something about the overall 'shape' of a piece of music. While they represent elements that unfold over time, we can capture them 'spatially' in a more condensed form so they can be viewed as a whole. This paper focuses on when and how these spatial representations of form first emerged, and why they took so long to become an established part of the discourse about musical form. Various techniques for representing musical forms diagrammatically are then examined more closely, such as traditional methods, and more complex analytical methods including Schenkerian and formal analysis that pay particular attention to musical hierarchies. This examination is used to support thinking around how the sequence of, and interaction between, educational parameters across time may be represented. Existing practices in education are then explored, that is, how teachers and learning designers are currently using inscriptions or diagrams to reflect on, shape or communicate their design ideas, asking: what kind of spatial representations of form do we already have in education? And how can a knowledge of spatial representation of musical form help us build on these in ways that would be useful to support those who design for, or teach in, hybrid learning spaces? 
While there are significant differences between musical and educational forms in terms of their parameters and context, the parallels between them provide an opportunity to reflect on the kinds of questions that are useful to ask in education when considering representations of form. The way descriptions and representations of large-scale structures evolved in the field of music offers education some starting points. It provides insights into the importance of clarity of purpose in developing representations of form, clues about what might be usefully included and omitted from such representations, and ideas about how they can be used to support designs for learning and the sharing of practice. While the focus of research to date has not been on drawing relationships between educational and musical representations of form, there is an increase in related research on sound and pedagogy and sonic practices in the classroom. These include studies by Wargo, Oliveira, and Brownell (2021) who advocate a multimodal approach to educational ethnography that brings sound into equal importance with the visual and textual, and Ceraso's (2018) work on sonic pedagogy and using multimodal listening. A further example is Elbow's (2006) 'The Music of Form', which examines the organisation of music to rethink the organisation of writing and in the process highlights the 'gulf between objects in space and events in time' (662).

Although they may be expressed differently in practice, music and education have many parameters in common, such as duration, dynamics, silence, proximity, gesture, spatial relationships and pace, to name a few. Texture - the quality created by the combination of different elements in music - is a parameter that has new resonances in education. While the 'texture' of a learning session may be interpreted in various ways in education, in the context of hybrid learning it could be used to refer to the relationship between the spatial layers that are created when some students are co-located and others are remote in time and place. This paper explores how representations of form may be used to visualise events and their relationships within and across these layers.

This study does not attempt to come up with specific solutions about how we can spatially represent form in hybrid learning sessions. Rather, it offers a series of ideas and questions that can be used to facilitate movement towards further developing approaches to spatial representations of form in education.

\section{Spatial Representations of Musical Form}

How we represent the abstraction of form both reflects and shapes the way in which we think about it. (Bonds 2010: 265).

By allowing us to take in the form of a work at a glance... diagrams by their very nature offer perspectives that verbal accounts alone cannot. (302).

What can we learn from the way spatial representations of form first emerged in the field of musical analysis? This section begins by considering the evolution of spatial representations in Western art music, and why they took so long to become commonplace in the discourse about musical form. It then provides a summary of the most widely used approaches to representing form including traditional methods, 
and more complex analytical methods that are capable of revealing more detailed musical hierarchies.

\section{The Evolution of Spatial Representations of Musical Form}

In writing about the spatial representation of musical form, Bonds (2010) notes that musical form can be approached from both temporal and spatial perspectives. 'The temporal perspective is a representation of form that involves 'a diachronic succession of events that unfold through time', while the spatial perspective represents form as a 'synchronous entity' (265). Temporal representations unfold through time and include a sequential description of events. Spatial representations, on the other hand, treat form as structure, taking a more comprehensive view, and are often represented diagrammatically to show the relationship of the parts to the whole in a single image' (265). While each can be considered separately, the two perspectives are interdependent. Bonds reminds us that written narrative accounts of music that describe a series of events often rely on spatial imagery, for example, 'a move to the dominant', or a 'return to the principal idea' (266). Similarly, the formal diagrams that represent overarching spatial form reflect the sequential events in a musical work. To summarise, musical form is both a process and a structure.

Before spatial representations were commonplace in musical analysis, music theorists relied on written descriptions of form (narratives) that focused on the unfolding of a sequence of events and their larger-scale relationships. Spatial representations of musical form did not appear until 1826 when the music theorist and composer Antoine Reicha used diagrams to accompany his written accounts of musical form (Bonds 2010: 266). To put this in perspective, an early well-established form of musical notation that was a precursor to modern musical notation - the neumatic notation of plainchant and secular songs in the medieval period - first appeared in the ninth century. So while musical notation had been well established for some time, it was another ten centuries before anyone attempted to represent the underlying structures of music visually. Figure 1 shows a representation Reicha included in his Traité de haute composition musicale to support a discussion of large binary form (Grande Coupe Binaire), a form now known as sonata form ${ }^{1}$. This was the first time a music theorist had attempted to depict musical form spatially (266). This synoptic diagram depicts the main sections of the work using broad arches, and the sub-sections nested within each larger section using sub-arches.

One of Reicha's motivations for including spatial representations was his belief that graphic depictions would 'better impress [themselves] into the memory of students' (Bonds 2010: 288). Another diagram presented in the same volume focuses more explicitly on proportional design, each section depicted by arches and sub-arches with attention given to the relative size of each part (Fig. 2). Bond points out that this use of spatial proportioning represented a huge advance in the history of musical analysis (288).

\footnotetext{
1 A form that was prevalent in Western tonal music from the middle of the eighteenth century.
} 
Reicha's "Grande coupe binaire" from his Traité de haute composition musicale, vol. 2 (1825), 300. Image courtesy of the Rare Book, Manuscript, and Special Collections Library, Duke University, Durham, North Carolina

Première partie, ou exposition des idées. MOTIF ou première idée mère./PONT ou passage d'une idée à l'autre./SECONDE IDÉE MÈRE dans la nouvelle tonique./IDÉES ACCESSOIRES et conculsion de la premère partie.

Première section de la seconde partie. DÉvElOPPEMENT principal, en modulant sans cesse./ARRÊT sur la dominante primitive.

Seconde section. Motif initial dans le ton primitif./Quelques modulations passagères avec les idées du pont./Transposition de la seconde tonique dans la tonique primitive, avec des modifications./CODA.

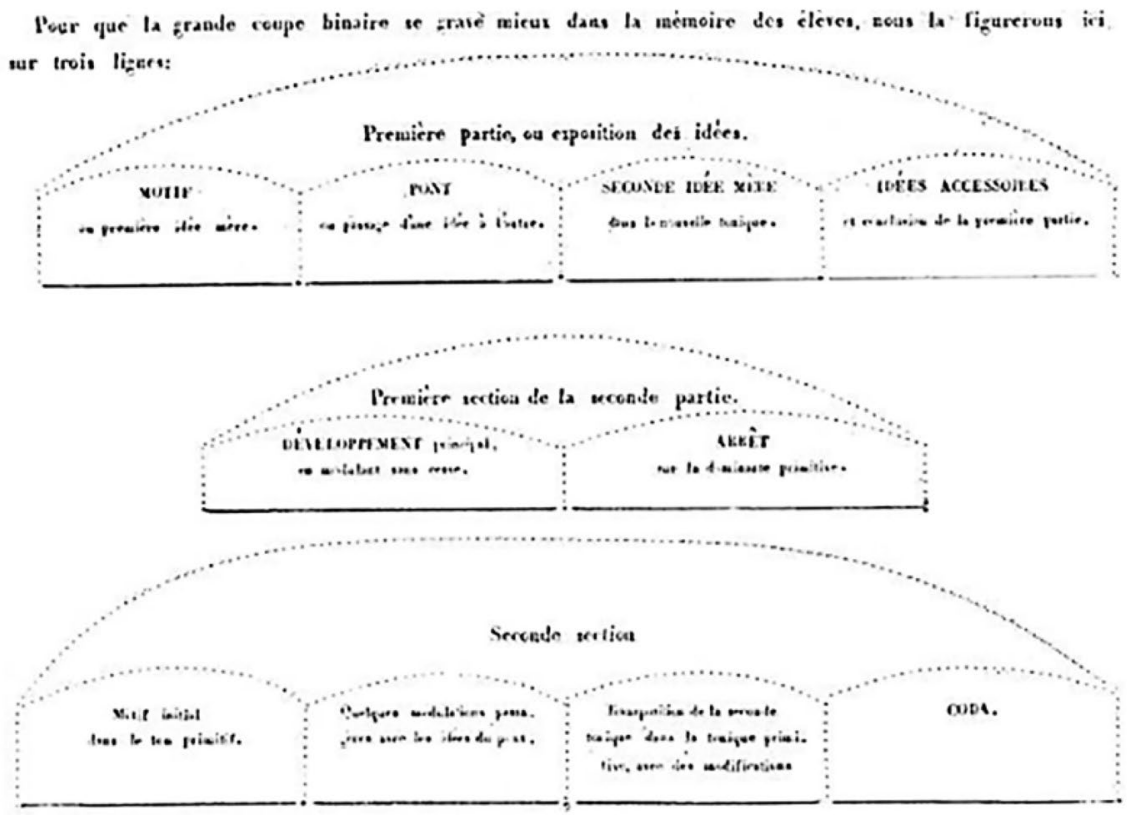

Fig. 1 Reicha (1826), Grande coupe binaire (Bonds 2010: 266)

While this was a big step forward for the field, only three other treatises used similar diagrams over the next seventy years, and it was not until the twentieth century that simple synoptic representations to depict traditional musical forms (discussed in the following section) became widely used (Bonds 2010: 290). Bonds considers the slow emergence of spatial representations of form in music 
The "Coupe du rondeau" from Reicha's Traité de haute composition musicale, vol. 2 (1825), 303. Image courtesy of the Rare Book, Manuscript, and Special Collections Library, Duke University, Durham, North Carolina

Premère section. Motif, suffisamment long, avec ou sans reprises./Exposition d'idées, développement accessoire. Seconde section. Motif da capo, abrégé./Nouvelle exposition d'idées dans d'autres tons. Developpement accessoire. Troisième section. Motif da capo, abrégé./Troisieme exposition d'idées dans d'autres tons. Développement accessoire. Quatrième section. Motif da capo, en entier, mais sans reprises./Développement remarquable, en rappelant ce qui est le plus saillant dans les trois sections précedentes./CODA.

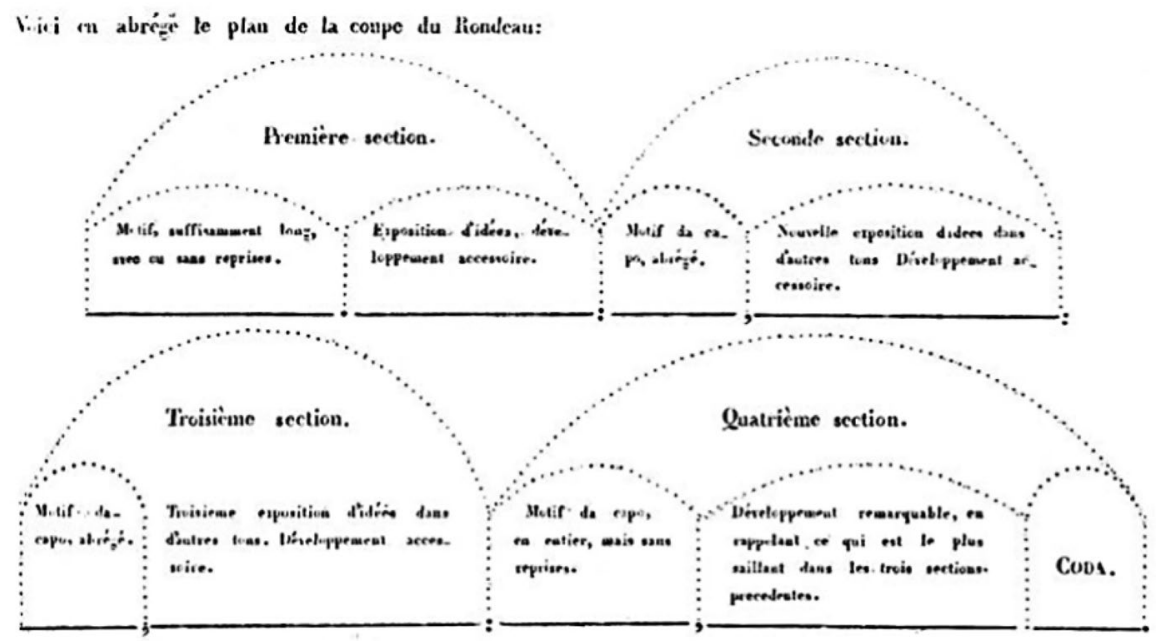

Fig. 2 Reicha (1826), Coupe du rondeau (Bonds 2010: 289)

to be particularly surprising given the strong historical relationship between music and architecture, in particular, the 'parallel between composing a work of music and constructing an edifice' (268). They both require a 'ground-plan' and the sketching out of a draft or outline. Even though conceptual parallels had been made between musical form and space long before Reicha's example, no one had depicted form in this way (270). Recent research in acoustic archaeology and aural architecture continue to explore such relationships, for example, Blesser and Salter's (2006) exploration of the audible attributes of physical space and how we experience space through listening.

Bonds (2010) identifies two basic principles on which spatial form rests:

1. Different manifestations of the same basic structure can be reduced to, or be described on the basis of, a set of common features that occur in a predictable sequence.

2. This series of events can be represented synchronically: a sequence of temporal features can be represented in a two-dimensional schema that reflects a synopsis of the relationship of the parts to the whole. (270)

The first principle was well established by the late eighteenth century (before Reicha's diagrams appeared). Prominent music theorists, such as Koch, began 
identifying and describing different structural levels related to form, for example the Anlage (the plan or outline), the Ausfurung (elaboration) and Ausarbeitung (refinement). ${ }^{2}$ By the end of the eighteenth century, music theorists recognised the idea of a linear, reductionist approach to form, and frequently relied on 'spatial imagery to describe the general outline or shape of a movement or work' (277). Rather than use diagrams, however, their approach to describing formal conventions was more like a set of instructions, or 'a series of step by step moves a composer could make to arrive at a large-scale whole' (277). Bonds uses the example of a geographical 'map' and its advantage over a written description of a landscape to point out that a map not only shows the 'starting point, route, landmarks, and destination of a journey but the proportional relationship of these points as well' (277). He notes that what was lacking for music theorists was 'the means by which to present diachronic events synoptically', pointing out that even simple timelines did not appear until the mid-eighteenth century (277). While a geographical map projects the dimension of space onto space, a diagram of musical form needed to map the dimension of time onto space (as would a 'map' of a learning session). This highlights the significant conceptual leap it would have taken for Reicha to produce his early representations of form (278).

While spatial representations of musical form were slow to emerge, they are now 'such a standard element in the discourse of musical theory, analysis, and pedagogy over the past century that when we think of specific manifestations like rondo or sonata form, we are more likely to conceptualize them in synoptic rather than temporal terms' (Bonds 2010: 302). Bonds describes how the relationship between the temporal and spatial aspects of form in music are influenced by the presence of a synoptic image:

We know that musical form is in one sense temporal: it reveals itself in performance only over the course of time; yet the power of the synoptic image is so great that in our minds the form of a work can become a kind of imagined space in which the music operates. (Bonds 2010: 302)

These ideas may be applied equally well to a learning session, which also reveals itself over the course of time (it is durational), yet with the support of a synoptic image, the form of the session may become 'a kind of imagined space' in which the learning takes place.

\section{Approaches to Musical Analysis and the Spatial Representation of Form}

There are two primary aspects of musical form - the surface pattern and the underlying process. Musical analysis is concerned with the ways in which these two aspects interact (Cook 1987: 260). The graphical representations that are produced to support musical analysis help theorists understand and communicate

\footnotetext{
2 These structural levels were not just of interest to music theorists. Composers such as Joseph Hayden were known to approach composition by laying out most of the prominent parts of a work spatially, then filling in the rest at a subsequent stage (Bonds 2010: 275).
} 
aspects of musical form, but they can also provide examples for composers to study (or ways of mapping out a structure to guide composition), and help performers memorise or familiarise themselves with the overall form of a piece of music.

Formal analytic techniques in music tend to focus on musical hierarchies, that is, they represent and 'discuss musical form in terms of groupings of events at successive levels' (Lerdahl 2015: 83). This might include motifs, phrases, groups of phrases and sections.

\section{Traditional Analysis}

To describe form in traditional analysis, letters of the alphabet (A, B, C, etc.) are used to indicate musical divisions brought about by the repetition, variation or presentation of new or contrasting material. Variations on a particular musical unit can be indicated by a superscript: $\mathrm{A}^{1}, \mathrm{~B}^{1}, \mathrm{C}^{1}$ etc.

The simplest analytical examples in music - binary and ternary form - are sectional. Binary form consists of a simple A-B structure, where A and B are two different musical ideas or themes. In the performance of a work in binary form, each section is usually repeated (A-A-B-B). A well-known example is the folksong 'Greensleeves'. Ternary form has a three-part structure, A-B-A, where the first section (A) returns at the end. A recognisable example is the nursery rhyme 'Twinkle Twinkle Little Star'. The 'da capo arias' of the Baroque period provide many examples of the form, such as 'The Trumpet Shall Sound' from Handel's Messiah. Variations on the form include simple ternary form and compound ternary form. These variations are distinguished by various stylistic presuppositions (associated with tonality, harmony etc.).

Other more complex forms include rondo form (A-B-A-C-A), consisting of a recurring theme alternating with contrasting themes (a classic example being Beethoven's 'Für Elise'), and sonata form, consisting at the broader level of three sections: an exposition, a development and a recapitulation. There are numerous variations on these schemas, and forms can be extended by adding further 'sections' such as an introduction or a coda. Other forms, more commonly associated with 'songs', include through-composed, where no large-scale section is repeated or returned (each stanza is set to different music), and strophic, where the same music is repeated in each stanza of a song.

Synoptic representations of form using letters (Fig. 3) provided an effective way of representing large-scale forms, emphasising the thematic structure of a work. They are used by analysts as a reference to describe similar musical works in terms of the level of abstraction from these standard forms, for example, as

Fig. 3 Synoptic representations of traditional music forms

Binary
Ternary
Rondo
Sonata
Through-composed
Strophic

Binary

Rondo

Through-composed Strophic
$A-B$

$A-B-A$

$A-B-A-C-A$

exposition, development, recapitulation $A-B-C-D-E$

$A-A-A \ldots$ 
elaborations or expansions on them. For early music theorists, analysing overall form involved 'assimilating it into one existing formal prototype or another' (Cook 1987: 9). In addition to being used by analysts, traditional musical forms were used in music schools to teach composition - they were patterns to be re-used (Cook1987: 9-10). Cook (1987) suggests that there was a tendency for early analysts to overemphasise thematic content and ignore aspects of the music that did not fit in. The word 'transitions' was used to describe non-thematic sections. Cook notes that this is problematic given that transitional passages can sometimes be 'the most intense and expressive' (9).

Design patterns and pattern languages are increasingly being generated in education to share design knowledge (Goodyear and Retalis 2010). Similarly, scripts such as those found in the computer-supported collaborative learning arena offer educators ways of structuring interactions (Villasclaras-Fernández et al. 2013). With the exception of the Learning Arches method (described later in this paper), ways of visually sequencing and representing such patterns to help educators orchestrate learning in complex environments are still underdeveloped. That is, we do not have comparable building blocks or schemas (well-understood structural patterns like binary and ternary form that can be visualised) to help us construct effective large-scale structures in a learning session that are underpinned by learning theory. Teachers do have access to practical resources such as lesson plan templates that provide guidance on aspects like how to align session learning outcomes with learning activities, and to consider which resources might best support those activities etc. It would be possible to produce similar synoptic representations of learning sessions to capture points in a session where repetition or variation occurred, or when new material was introduced. For example, many learning sessions would begin with a recap of concepts previously learned, followed by the introduction of new material, followed by an opportunity to practice applying the concepts introduced (perhaps with some variations), and conclude by revisiting the key points at the end in a wrap-up session.

There may also be forms attached to specific pedagogies, such as studio learning and teaching. Studio learning structures include four main elements: mini-lecture or demo, students-at-work, critique and exhibition (Hetland et al. 2013). The sequencing of these elements, however, would be dependent on the learning objectives of the session. Could synoptic representations be useful for communicating a range of ways that these elements could be sequenced to meet different learning objectives? While these rudimentary representations may need to be accompanied by descriptive accounts to support implementation, they would allow teachers and learning designers to reflect on and shape the overall design of a session and more deeply consider the role these large-scale structures have on the learning experience.

\section{Schenkerian Analysis}

The spatial representations of musical form best known today are those produced by Heinrich Schenker. Also known as 'voice leading graphs', their purpose is to 'integrate the local and global issues of voice-leading, harmony and form' (Bonds 2010: 
299). Schenkerian analysis is a far more detailed graphical approach to 'uncovering' and communicating musical form than the traditional methods outlined above. That is, more can be captured in the graph itself rather than relying heavily on descriptive notes to accompany simple synoptic representations. The aim is to 'omit inessentials to highlight important relationships' and reveal the internal coherence of the music (Cook 1987: 28). The emphasis is to uncover large-scale linear formations and their contribution to creating directed motion towards harmonic goals (35).

Figure 4 shows an example of a voice-leading graph based on Schenker's own analysis of J. S. Bach's 'C Major Prelude'. The graph combines conventional music notation with other symbols and includes three layers. The top line represents the fundamental structure of the work, the second line shows the middle ground, and the bottom line (most closely resembling a musical score) is the comprehensive foreground graph. These structural layers are arranged to preserve 'a sense of spatial proportioning' (Bonds 2010: 299).

It is Schenker's integration of temporal and spatial perspectives that 'has contributed, in no small measure, to the widespread adoption of the principles that underlie his 'graphs'. He consistently resisted the top-down approach to form exemplified by diagrams designed to represent abstract, ideal types' (Bonds 2010: 299). It is important to note that his primary purpose, however, was analysis rather than compositional pedagogy. The complexities associated with Schenkerian analysis are significant, with many musicians and theorists finding the method difficult. While detailing these complexities is beyond the scope of this paper, this brief account of the approach has been included to demonstrate a way of representing musical form that reveals the relationship between different structural layers and the contribution of large-scale linear formations to creating directed motion towards harmonic goals. That is, while the specifics of Schenker's maps are not as important in this discussion, the graphs could be used to inspire a more useful design and analysis for hybrid learning spaces that has greater potential than the lesson plan format that is more linear and temporal in nature.
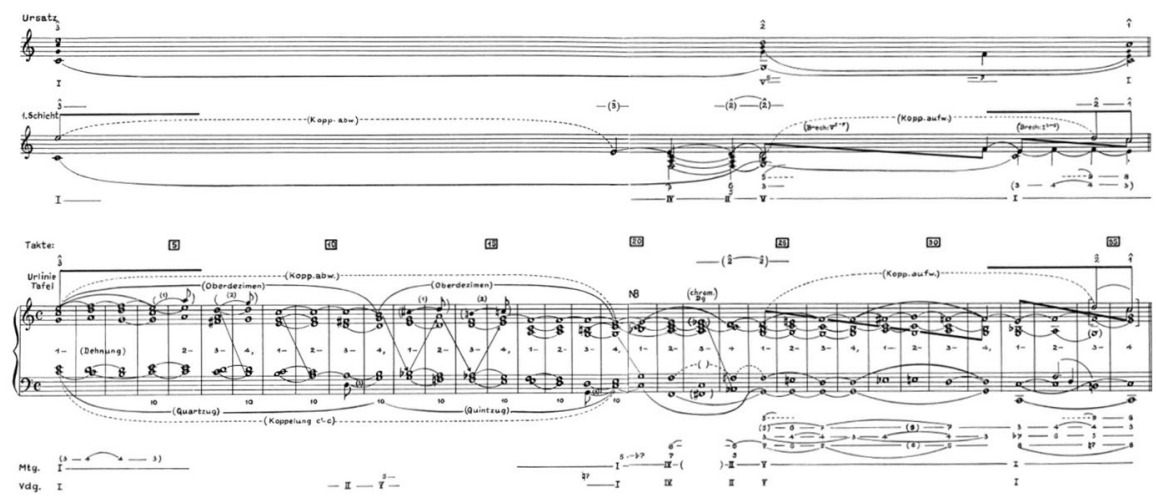

Fig. 4 Analysis of the C Major Prelude (Schenker 1969, pp. J. S. Bach 2/3 and 3/3) 
A comparison between representations of traditional musical forms (which often led to analysts trying to fit pieces of music into these archetypes) and Schenker's voice-leading graphs (where the form of the work itself is revealed) provides an opportunity to reflect on the importance of understanding the aims behind different analytical approaches. In education, we need to reflect on the purposes that spatial representations of form would serve.

\section{A Comparison with 'Formal analysis'}

'Formal analysis' of music involves 'coding music into symbols and deducing the musical structure from the pattern these symbols make' (Cook 1987: 116). It is usually associated with a more detailed approach to coding than is used in traditional methods. Figure 5 shows a range of diagrammatic representations of form based on formal analysis.

While formal analysis and Schenkerian analysis both focus on examining a series of structural levels from the most determinate to the least determinate, the interest in the psychological experience of time is no longer there in formal analysis. That is, Schenkerian analysis focuses on how the music is experienced as 'directed motion' (Cook 1987: 122), while formal analysis is concerned more with how the musical notation can be coded 'so that its formal unity will become self-evident'. Schenker uses the perceptual experience of music 'as its raw material', while formal analysis primarily analyses the musical score (122-123). This distinction provides further impetus for revisiting the question about the purpose of creating spatial representations.

Formal methods of analysis have not had a significant impact on the 'tonal repertoire'. They are more commonly applied to early music, and non-tonal music written in twentieth-century contemporary music (Cook 1987: 151), and as shown in Fig. 5 (a), they are not always represented temporally.

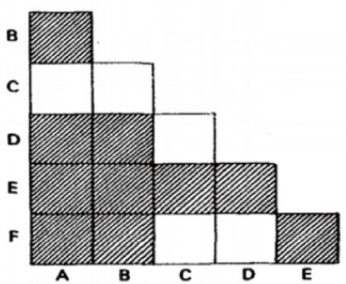

(a) 'Mileage' chart

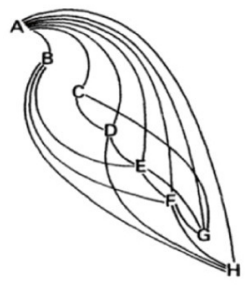

(b) Form-chart

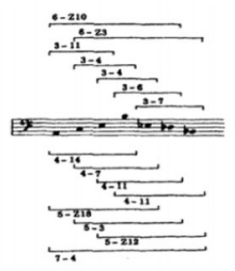

(c) Imbrication (overlapping arrangement)

Fig. 5 Different diagrammatic representations of form based on 'formal analysis' in music (Cook 1987: 130, 146-147) 


\section{How Does Musical Form Help Us in Education?}

As in music, the form of a learning session can be approached from both temporal and spatial perspectives. The temporal perspective of a learning session involves a succession of events that unfold through time. A temporal representation of a learning session might involve a sequential description of events that unfold through time (akin to a lesson plan or running sheet). A spatial perspective on the other hand would represent form as a synchronous entity. That is, it would take a more comprehensive view, and could be represented diagrammatically to show the relationship of the parts to the whole in a single view. For example, it would allow you to see elements in a learning session that are revisited, and variation in the structure of peer activities such as whether students are working in pairs or groups.

It was highlighted earlier that music and education have many parameters in common. These include duration, dynamics, silence, proximity, gesture, spatial relationships and pace. It was identified that learning sessions have a textural quality and that this may be more pronounced in the hybrid learning context, with some students co-located and others remote in time and place. The discussion above revealed that it took many decades for spatial representations of form to become part of the establish discourse on musical form - they were slow to emerge. This prompts the question of why spatial representations of form have not surfaced in education to guide the teaching, design and analysis of learning sessions. In more didactic forms of teaching, lecture notes or slides might be enough to serve the purpose of guiding a teaching session. However, as education increasingly moves away from transmission models of teaching to incorporate active and interactive pedagogies, and as hybrid teaching becomes more prevalent, it is likely that the complexities of the learning environment will prompt more focused investigations of how spatial representations of form can support teaching practitioners.

The musical lens helps to raise questions about the purpose of spatial representations of form in education and whether such representations could serve various purposes. For example, could they be used as both a teaching tool (to education students or teachers in a professional development context) and to help teachers and learning designers reflect on and shape learning sessions? If in education we had a range of archetypal forms for a learning session, would it then be possible to use them as an analytical tool to help us understand how teachers and others involved in learning design have varied, elaborated on or extended these forms to meet learning needs? That is, to consider the extent to which observed forms are abstracted from 'standard' formal patterns. Hybrid learning sessions might be thought of extensions of traditional forms.

Even before spatial representations of music emerged, theorists were interested in describing the different structural layers of music: the plan or outline, how these were elaborated on and the more detailed refinement of ideas. This was later exemplified in Schenker's approach to representing musical form, which shows the fundamental structure of the work, the 'middle ground' and a more comprehensive foreground graph. What do these structural layers look like in a learning session, and how might they take into account key dimensions of the learning environment 
such as tasks, social dynamics and the physical or digital learning environment? To answer these questions, we need to reflect on the benefits of being able to see form as 'a kind of imagined space' in which the learning activity emerges.

As suggested earlier, while teachers can access practical resources such as lesson plan templates for guidance on developing a lesson, they do not have access to models or schemas comparable to the traditional musical forms described earlier. It would be useful to consider what such schemas would look like in education, how elements like repetition, variation and the introduction of new material could be represented and how they might be used to support teachers in shaping the overall design of a session and reflecting on the pedagogical rationale for the choice of large-scale form.

The synoptic representations of traditional musical forms also prompt reflection on the role of transitions in a learning session, and how best to represent them, particularly given that such transitions take on a heightened significance in hybrid learning contexts. Managing students in a classroom and online simultaneously presents significant challenges when moving from one activity to the next. As in Schenkerian analysis, spatial representations of the form of a learning session would need to focus on omitting inessentials and highlighting important relationships. In particular, it would be beneficial to capture how certain elements in a session contributed to the overarching learning goals. One lesson we can learn from Schenkerian analysis, however, is that overly complex representations are more likely to be used by analysts than practitioners.

A discussion of formal analysis in music, which involves using a broad range of techniques to code music into symbols to reveal musical structures, demonstrated a notable difference in purpose when compared to Schenkerian analysis. While Schenker was more concerned with representing how the temporal qualities of music are experienced, formal analysis focuses more on the objective musical score. As we do not have an equivalent to musical notation in education, and our focus is on the student learning experience, this suggests that the diagrammatic techniques used in formal analysis may not be as useful to education. They may, however, prompt reflection on the kinds of symbols we might use to represent different 'dependent' and 'non-dependent' hierarchical relationships that take place in a learning session.

The discussion of musical form above suggests that the way we choose represent the abstraction of form of a learning session will both reflect and shape the way we think about it. As in music, spatial representations could potentially be used to support pedagogical, theoretical and analytical discourse.

\section{What Do We Have to Work with in Education Already?}

Compared to the field of music, education appears to have limited examples of spatial representations of form to support practitioners. While there are many techniques that teachers and learning designers use to represent formal elements, there are no established approaches that are used widely and consistently. In the discussion above, it was revealed that different approaches to representing form in music have been taken up to greater or lesser degrees by practitioners (analysts, composers 
and performers) due to their complexity. Therefore, this section begins with the question of how teachers and learning designers naturally 'inscribe' in the process of designing for learning. It then describes the Learning Arches (LAs) approach to visualising large-scale form, and considers the structural dimensions of complex learning environments and how they might be represented. The section concludes with some examples of emerging representations of hybrid learning forms.

\section{How Do Teachers and Learning Designers Naturally Inscribe?}

Wardak (2016) notes that very little is known about the way educational designers use inscriptions to communicate ideas. Inscriptions refer to 'visual marks, sketches, or images made through the act of writing, drawing, and engraving onto a surface' (260). The study examined how a group of designers created and used inscriptions across several educational design meetings (258). A key finding of the study was that 'the meaning of elements used in inscriptions depended on the context of their use' (279). This contextual dependence may add to the challenge of arriving at a consistent visual language or way of representing educational parameters and their interactions that will meet teachers' needs. The study found that inscriptions were often created at the conceptual phase of the design process (280). It reinforces the idea that visual representations can help us to both reflect on and shape what it is we are designing. While this idea is well recognised in music (via notation and more abstract representations) and other durational art forms such as dance (with its own form of notation), it is not common practice in education.

The different types of inscriptions identified in Wardak (2016) included: thinking marks (simple annotations), composite written (e.g. lines connecting words to indicate a relationships), pure lists (e.g. a sequence of numbers and bullet points), composite lists (e.g. lists involving lines and arrows to connect list items), abstract diagrams (combining iconic and symbolic elements) and concrete diagrams (depicting the object they represent) (266). The reasons educational designers used these inscriptions included capturing ideas and decisions made, inscribing solutions, and demonstrating ideas (274). Spatial representations of form produced to guide a learning session would share similar purposes. Wardak identifies a number of good practices associated with visual representations, all of which would be desirable in spatial representations produced to capture the form of a learning session:

- Chunking information (making it more efficient to find information)

- Salience (illustrating what is important)

- Layout and position of visual elements (to communicate meaning)

- Embellishment (visual cues to make certain elements stand out) (261-262).

The study concludes that "early educational design drawings should be retained and recorded, for reflection and learning within a design project and to help in training newcomers to the area, and to stimulate the development of a richer vocabulary with which to talk about drawings in educational design' (Wardak 2016: 280). Wardak acknowledges that these approaches are generally not incorporated into our 
working practices and agrees that 'the ultimate goal for educational design might be the development of a possible visual language, akin to a music notation system, which can make communicating design ideas more efficient' (280). This resonates with research that has examined the changing role of the designer in contemporary design practice, where one of the emerging roles for designers across different design fields is to be able to visualise intangibles (Wilson and Zamberlan 2015; Wilson, Huber, and Bryant forthcoming 2021).

\section{Structural Dimensions of Complex Learning Environments}

The Activity-Centred Analysis and Design (ACAD) framework helps us to consider the core structural dimensions that might feature in spatial representations of a learning session (Goodyear and Carvalho 2014). As shown in Fig. 6, the framework includes three dimensions that influence learning activity. These include set, epistemic and social design. Set design refers to the physical and virtual learning and teaching environment and includes tools, artefact and resources; epistemic design involves a consideration of tasks; and social design includes how learners are grouped and the roles and responsibilities we assign to them. Each dimension is open to alteration through design. As designers, we can modify the conditions across these dimensions to influence the quality of the learning activity that emerges. The fourth dimension - emergent activity — is not open to alteration through design. It involves acts of co-creation and co-configuration at 'learntime' and determines the learning outcomes.

The framework provides a way to think about how various structural elements come together in complex learning environments. The question addressed in the present study is: how might these elements be best represented by teachers and

Fig. 6 The ActivityCentred Analysis and Design (ACAD) framework (Carvalho and Yeo$\operatorname{man} 2018:$ 1126)

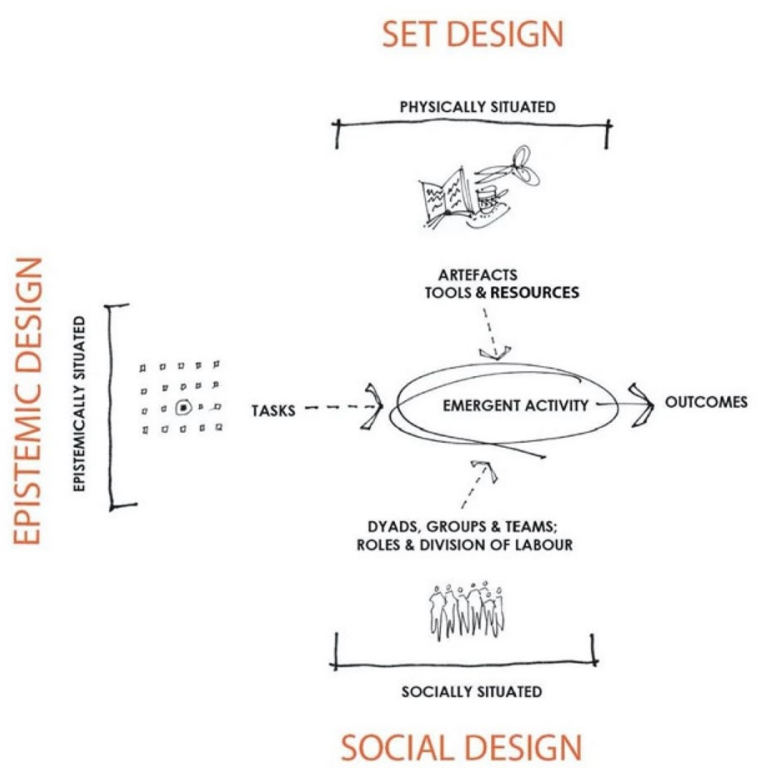


designers when planning for a learning session in a hybrid space? How can we capture 'new distributions of activity across time, space, media, organisations, and people' (Carvalho, Goodyear, and de Laat 2017: 1)?

Some similarities could be made between the structural elements of the ACAD framework, and the structural layers represented in Schenker's voice-leading graphs, which contain fundamental structures, middle grounds, and foreground structures and the relationships between them. In a professional development workshop co-facilitated by the author, the ACAD framework was used as a tool to support participants in designing an active lecture (Fig. 7). The framework was integrated into a timeline tool that asked participants to design and structurally represent an active lecture by mapping the task, set and social design dimensions and their relationships over time. The final 'map' could be considered one example of a spatial representation of form for a learning session. The question is, how could such a map also accommodate features that would represent the textural layers of a hybrid learning session and the interrelationship between events? Carvahlo, Goodyear and de Laat (2017) state that set, social and epistemic dimensions of the framework are entangled in real-world activity. In the case of hybrid learning, we need to consider the extent to which this entanglement occurs across boundaries of place (in-class and remote).

\section{Learning Arches}

One existing approach to representing form to support educational design is the Learning Arches (LAs) method, which creates a 'big picture' that visually represents the student learning journey (Kavanagh 2019: 4). The method allows for the exploration and refinement of the interlinking of skills, knowledge, attitudes and values. As it is visual, it can be used as a shared communication and collaboration tool to support co-design processes between educators, students, and other stakeholders. The aim is to provide a way to 'see the curriculum beyond solitary blocks and stimulate flow, connection and continuity of learning' (4).

As can be seen in Fig. 8, the Learning Arches technique shares notable similarities with Reicha's early spatial representations of form in music (Figs. 1 and 2). It uses nested arches to represent the grouping of events and their relationships over

Fig. 7 Example provided in a workshop to guide participants in the process of mapping the dimensions of the ACAD framework across time to build active learning into their lectures

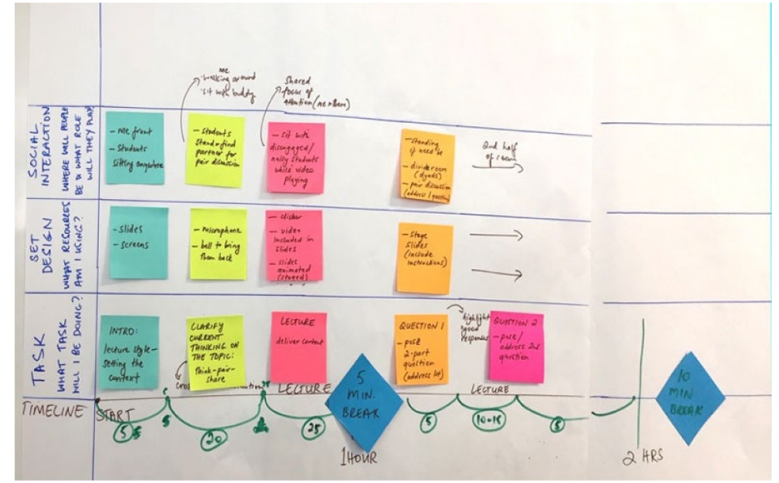


Fig. 8 An example of the Learning Arches method in practice (Kavanagh 2019)

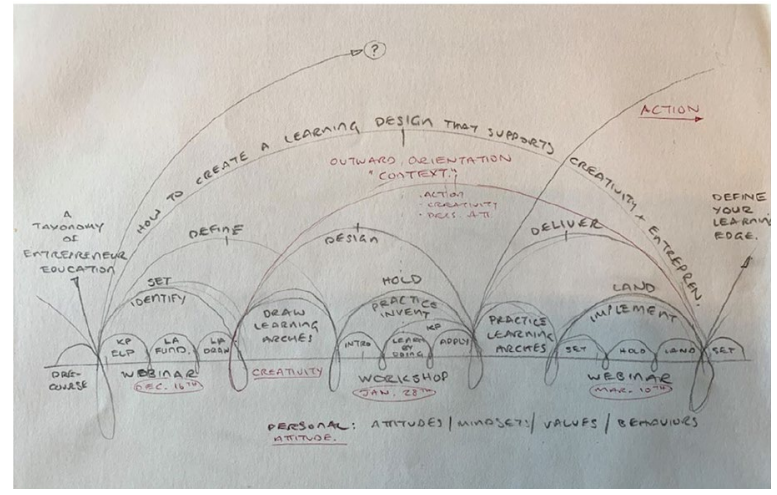

time. The three primary steps involved in implementing the method include setting, holding and landing arches. Setting involves representing and implementing a new 'phase' in the learning process on the timeline. Holding involves 'facilitating and leading... the learning experience and the learning space both inside the arches and between them' (the space inside an arch is referred to as a 'learning space') (Kavanagh 2019: 12). Landing involves completing a phase of learning before setting off on the next phase (representing some form of reflective action). In this sense, the method draws attention to the importance of transition points - where one phase ends and another begins.

The Learning Arches method is most commonly used to map the student learning journey throughout an entire course, program or semester rather than to represent a single learning session. How can a knowledge of musical form be used to build on the learning arches method as a way of representing the form of a single lesson, and in particular, to accommodate and represent the relationships that are key to hybrid learning and teaching? Furthermore, how can the structural dimensions of the ACAD framework be combined with these ideas to best represent the interplay of parameters in a hybrid learning session over time? As was demonstrated, the evolution of spatial representations of form in music showed Reicha's arched representations gradually replaced, first, by more rudimentary synoptic representations, and then later, by more complex graphic representations such as Schenkerian analysis, which was considered a more comprehensive method for representing event hierarchies and their global relationships. The issue that arose, however, was that that they became more a tool for analysts and less useful for those creating and performing music.

In addition to the arches themselves (which can be 'standard' or 'looped' at their setting and landing points), the Learning Arches method uses language, symbols (such as diagonal dotted lines across a timeline to represent increasing levels of challenge, expectation and ambition), and abbreviations, ${ }^{3}$ some of which are

\footnotetext{
${ }^{3}$ Examples of abbreviations include: AL (active literature), CD (creative disturbances), KD (knowledge disturbance) and HS (hotspot).
} 
associated with particular levels (macro, meso and micro). Elements that appear above the timeline represent the known aspects of the curriculum, while those appearing below the line represent aspects of the 'hidden' curriculum. Arches that group smaller arches to show interconnections (between skills, knowledge, attitudes and values) are referred to as X-level arches (Kavanagh 2019: 23).

\section{Hybrid Learning Events and Their Representation}

Due to the rapid transition to online learning resulting from Covid-19, universities have had to quickly develop and communicate ways of implementing hybrid learning. Now more than ever, the sector has needed a more efficient visual language to communicate ideas and support teachers in implementing new structures of teaching and learning. Figure 9 shows some simple representations of various options for hybrid (in this case Hyflex) learning sessions.

While the sequence of the learning session in each case is represented vertically rather than on a horizontal timeline, three possible hybrid models are demonstrated. Each begins with an introduction and wrap-up, but the middle section of the session varies, using different combinations of 'set' and 'social' dimensions. How might these be built upon to create more comprehensive spatial representations of form to support hybrid learning, that also incorporate the tasks students undertake, and the flow of information between learning and artefacts that emerge from students in the classroom and students learning remotely? Not surprisingly, graphic representations of hybrid learning have started to emerge, but they often fall short of representing both the temporal and spatial aspects of a learning session.

At this point, it is useful to consider the kinds of events, specific to hybrid learning and teaching, that might be included in spatial representations of form in a learning session. In music, to represent form spatially, we might be looking for 'surface features such as recurrences, changes of texture, and fermata' (pauses) and their relationships (Cook 1987: 118). We might also be looking at 'large-scale repetitions, motivic connections, points of high tension or release' etc. (237). Mor,
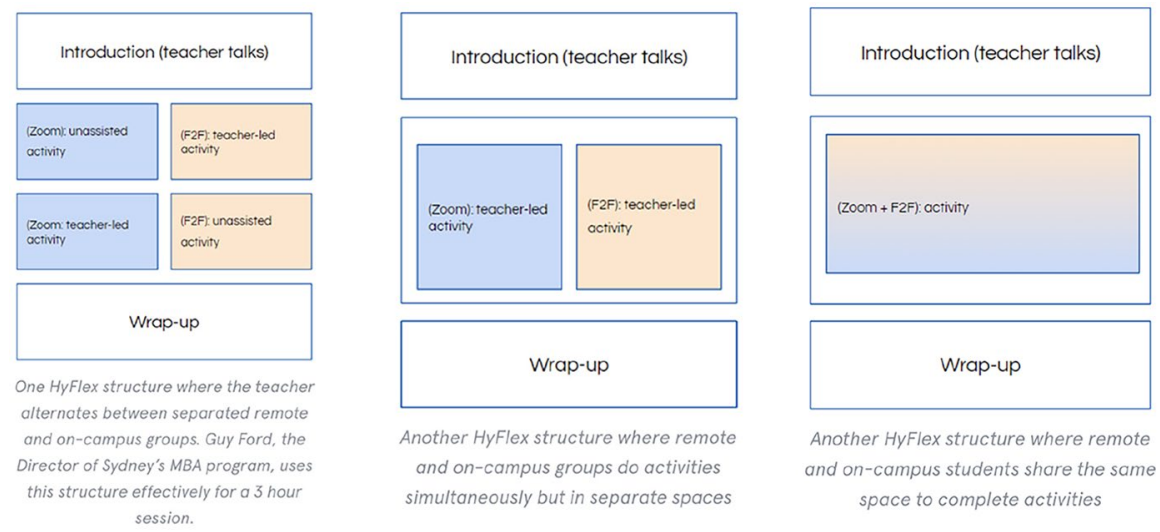

Fig. 9 Representations of form for Hyflex learning sessions (Kalman, Frawley, and Liu 2021) 
Dimitriadis, and Köppe (2020) list a number of 'design patterns' for hybrid spaces such as: guided versus unguided activity, periods of time where students receive immediate support or feedback, the translation of digital activities into the physical world and vice versa, remote buddies and interactive tangible objects that can easily move between spaces (6-7). Hybrid learning sessions may also involve points at which data is gathered and then revisited during the learning session - an event described by Cohen, Nørgård and Mor (2020) as 'double loop learning' (1040).

Representations of form could also indicate points in a learning session where one or more teachers are needed. For example, for some periods of time students might be working together on a hybrid activity involving co-located and remote students, and for other periods of time all co-located students might come together with one teacher, and all online students might come together with another teacher. Some of these arrangements are captured in the rudimentary diagrams shown in Fig. 9. Existing patterns for hybrid learning include more specific roles for teachers or those helping to facilitate hybrid learning sessions, such as the role of the 'technology concierge' (Köppe, Nørgård, and Pedersen 2017). Spatial representations of hybrid learning sessions can be increasingly informed and represented by hybrid design patterns as they emerge.

\section{Representing the 'Spaces-in-Between': Orthographic Drawings}

While the representation of the structural elements of the ACAD framework mapped over time (shown in Fig. 7) and the Learning Arches technique (Fig. 8) both offer ways of spatially representing the form of a learning session, neither currently have the capacity to represent relationships between the structural layers that are introduced in a hybrid learning context. Orthographic drawings may provide some insights into how this could be achieved. An orthographic drawing is a common method of representing three-dimensional objects in two dimensions.

The advantage of an orthographic representation is that it does not include vanishing points like in a perspective drawing, but instead, allows the viewer to observe the structure and relationship between layers more clearly. Figure 10 represents the relationships between spatial layers in a hybrid lesson based on the structural dimensions of the ACAD framework. In the task dimension, it shows that over the 60-minute duration of the lesson, co-located students and those working remotely online are engaged in the same tasks, with the exception of the 10-minute task represented in orange. In the set dimension, it shows that students are sometimes all 'tuned in' to the same shared 'space' across boundaries (i.e. with a single shared focus of attention) and at other times they are 'located' in separate spaces (for example, with students in Zoom sharing the same environment and resources, and those in the classroom sharing the same environment and resources). In the social dimension, it shows whether students are working or interacting as a whole group, or in groups determined by their 'location' (face to face or remotely online). The diagonal lines indicate that groups consist of a mix of co-located and remote students (for example, to construct joint digital artefacts). 
Fig. 10 Orthographic drawing showing relationships between spatial layers in a hybrid classroom based on the structural dimensions of the ACAD framework

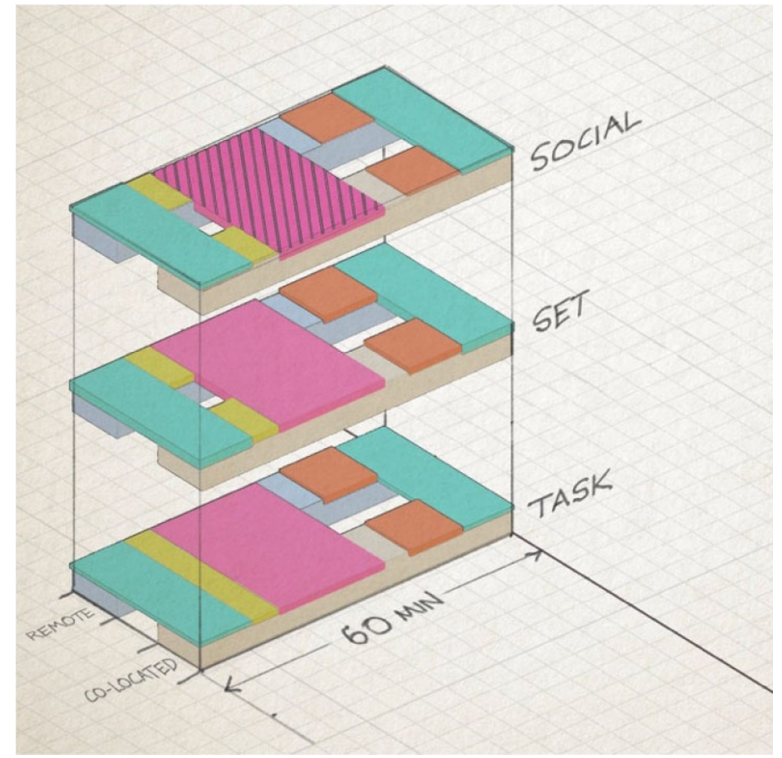

Figure 11 provides an alternative way of representing the student learning journey and how certain 'events' are managed across spatial boundaries. While the structural dimensions of learning (task, set and social) are not explicitly represented, the arrangements associated with these dimensions could be plotted on this more textural version of the learning arches. In this example, the introduction in the first 10 minutes of the lesson might suggest a single shared focus of attention by students in different locations on a mini-lecture or demonstration given by the teacher (the event bridges the divide between locations). The diagonal lines on the pink arch between 15 and 35 minutes might indicate that students are working in groups, and those groups consist of a mix of students working in-class and remotely. The event between 40 and 50 minutes (represented in orange) might suggest that students in-class are working in groups on one task, while students working remotely are

Fig. 11 Orthographic drawing representing learning arches across spatial boundaries

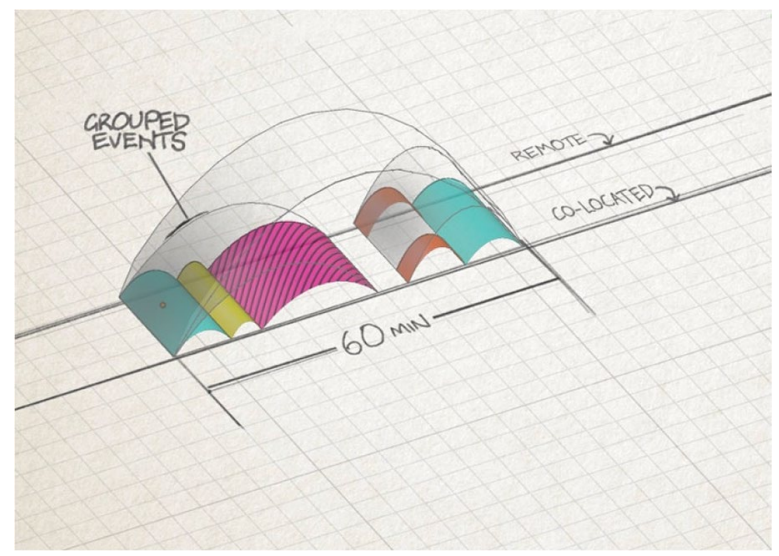


working in groups on a different task. The arch in the final 10 minutes suggests that students come back together for the session wrap-up.

By bringing together Schenkerian analysis with the Learning Arches method, it may be possible to develop a three-dimensional model for education that would facilitate and support more effective planning, design and analysis of classes in hybrid learning spaces. In doing so, we may also be able to help educators in the process of 'orchestration', that is, 'how a teacher manages, in real time, multi-layered activities in a multi-constraints context' (Dillenbourgh 2013: 487). Fawns (2019) reminds us of the importance of progressing from 'naïve conceptions of digital education and, indeed, non-digital education, to a recognition that considered, practically and theoretically informed design and orchestration are crucial, no matter what form teaching takes' (141).

\section{Discussion}

This paper set out to explore ways that spatial representations of form might support designers and teachers with the complexities involved in using hybrid learning spaces. These complexities arise from the number of potential social and spatial arrangements available to the teacher, as well as the technological challenges involved. The recent upsurge of hybrid learning has created a need to design and communicate possible hybrid learning and teaching models within our institutions and across the sector efficiently and effectively. This paper has argued that spatial representations of hybrid forms may have the potential to assist in this process. While it did not attempt to come up with specific solutions about how we can spatially represent form in hybrid learning sessions, it outlined some ideas and questions to facilitate movement towards further developing approaches to spatial representations of form in education. Such representations may be useful in shaping, refining and examining networked spaces and 'the different ways the component elements are integrated into a meaningful whole' (Ravelli and McMurtrie 2017: 111). As suggested by Goodyear (2020), in complex learning environments we need to focus on 'higher level, more abstract, descriptions of how such work is done...' (1045).

This study has also revealed the complexities of representing the form of a hybrid learning session in a single graphical image. Unlike music, education does not have established and accepted ways of representing large-scale form, let alone in the very complex environments associated with hybrid learning. Furthermore, the prevalence of networked and hybrid learning has led to researchers offering new ways of conceptualising space in education, such as the idea of space as the enactment of educational practices and the product of interrelations (Gourlay and Oliver 2017), and as a 'dynamic entity which is produced by the social and material interactions which take place "within" it' (Gallagher, Lamb, and Bayne 2017: 87). In a discussion about what recent conceptual frameworks such as 'entanglements' and 'meshworks' can bring to our understanding of learning spaces, Boys (2017) makes a distinction between conceptual and situated spaces and refers to 'spaces in-between' and the 'complex intersections between worlds' (60). These spaces in-between have been demonstrated in various ways through the representations of forms examined in this 
paper, such as the 'learning spaces' between arches in the Learning Arches method, and the spaces created by new textural layers in hybrid settings between students learning together in a classroom and those learning remotely.

Further complexity is introduced by the notion that 'spaces' in education are always in flux. For example, Gourlay and Oliver (2017), who draw on theories of space as social phenomena, note that conceptual spaces are constantly generated by students, reflecting the idea that space is always 'under construction' (Massey 2009 in Gourlay and Oliver 2017: 77). How might it be possible to represent temporal and spatial elements of form where students create their own 'spaces' for learning? If diagrammatic representations of spatial relationships are useful to learning designers and teachers, then at what 'level' should we be representing these relationships given that hybrid learning involves spaces 'opening up' which we cannot steer or predict - what do they offer? Representations need to allow room for flexibility, improvisation and emergence. This relates to the aspect of the Learning Arches method that emphasises how teachers 'hold' spaces for learning as facilitators.

Research might also seek to further understand ways in which visual representations support social aspects of design, that is, as teams of educational designers increasingly 'need to collaborate with a range of experts from various domains' (Wardak 2016: 281). It would be valuable to gain a better understanding of the benefits of drawing in educational design, and how it can 'aid in developing a design culture, similar to other design fields, where ideas are communicated using drawings, early sketches are retained and referred back to in design conversations, and students are trained in using visual representations for communication of ideas' (280). Considerations that preoccupy musical analysts are closely aligned with things that preoccupy composers. Similarly, in education, the interests of those analysing the structural elements of learning are closely related to the interests of learning designers and teachers. Spatial representations of form that serve the needs of both theorists and educators would be particularly useful at a time when educators are expected to move flexibly between different learning and teaching environments and navigate the complexities of hybrid learning spaces.

Acknowledgements Original drawings in Figures 10 and 11 are produced by Tam Morris (illustrator) in collaboration with the author.

Availability of Data and Material Not applicable.

Code Availability Not applicable.

\section{Declarations}

Conflict of Interest Not applicable.

\section{References}

Bonds, M. E. (2010). The spatial representation of musical form. Journal of Musicology, 27(3), 265-303. https://doi.org/10.1525/jm.2010.27.3.265.

Blesser, B., \& Salter, L. (2006). Spaces speak, are you listening? Experiencing aural architecture. Cambridge, MA: MIT Press. 
Boys, J. (2017). Finding the spaces in-between: Learning as a social material practice. In L. Carvalho, P. Goodyear, \& M. de Laat (Eds.), Place-based spaces for networked learning (pp. 59-72). New York: Routledge.

Carvalho, L., Goodyear, P., \& de Laat, M. (2017). Place, space, and networked learning. In L. Carvalho, P. Goodyear, \& M. de Laat (Eds.), Place-based spaces for networked learning (pp. 1-10). New York: Routledge.

Carvalho, L., \& Yeoman, P. (2018). Framing learning entanglement in innovative learning spaces: Connecting theory, design, and practice. British Educational Research Journal, 44(6), 1120-37. https:// doi.org/10.1002/berj.3483.

Ceraso, S. (2018). Sounding composition: Multimodal pedagogies for embodied listening. Pittsburgh, PA: University of Pittsburgh Press.

Cohen, A., Nørgård, R. T., \& Mor, Y. (2020). Hybrid learning spaces - design, data, didactics. British Journal of Educational Technology, 51(4), 1039-1044. https://doi.org/10.1111/bjet.12964.

Cook, N. (1987). A guide to musical analysis. London: Oxford University Press.

Dillenbourg, P. (2013). Design for classroom orchestration. Computers \& Education, 69, $485-492$. https://doi.org/10.1016/j.compedu.2013.04.013.

Elbow, P. (2006). The music of form: Rethinking organisation in writing. College Composition and Communication, 57(4), 620-666.

Fawns, T. (2019). Postdigital education in design and practice. Postdigital Science and Education, 1(1), 132-145. https://doi.org/10.1007/s42438-018-0021-8.

Gallagher, M. S., Lamb, J., \& Bayne (2017). The sonic spaces of online distance learners. In L. Carvalho, P. Goodyear, \& M. de Laat (Eds.), Place-based spaces for networked learning (pp. 87-99). New York: Routledge.

Goodyear, P. (2020). Design and co-configuration for hybrid learning: Theorising the practices of learning spaces design. British Journal of Educational Technology, 51(4), 1045-1060. https://doi.org/10. 1111/bjet.12925.

Goodyear, P., \& Carvalho, L. (2014). Framing the analysis of learning network architectures. In L. Carvalho \& P. Goodyear (Eds.), The architecture of productive learning networks. London, UK: Routledge.

Goodyear, P., \& Retalis, S. (Eds.). (2010). Technology-enhanced learning: Design patterns and pattern languages. Rotterdam: Sense Publishers.

Gourlay, L., \& Oliver, M. (2017). Students' physical and digital sites of study: Making, marking and breaking boundaries. In L. Carvalho, P. Goodyear, \& M. de Laat (Eds.), Place- based spaces for networked learning (pp. 73-86). New York: Routledge.

Hetland, L., Winner, E., Veenema, S., \& Sheridan, K. M. (2013). Studio thinking 2: The real benefits of a visual arts education. $2^{\text {nd }}$ Ed. New York: Teachers College Press.

Kalman, E., Frawley, J., \& Liu, D. (2021). Tips for teaching in Hyflex. Teaching@Sydney, 21 March. https://educational-innovation.sydney.edu.au/teaching@sydney/tips-for-teaching-in-hyflex/. Accessed 10 October 2021.

Kavanagh, S. (2019). Learning Arch Design. Kaospilot. https://www.academia.edu/40605001/LEARN ING_ARCH_DESIGN_USERS_MANUAL. Accessed 10 October 2021.

Köppe, C., Nørgård, R. T., \& Pedersen, A. Y. (2017). Towards a pattern language for hybrid education. In C. Kohls (Ed.), Proceedings of the VikingPLoP 2017 conference (April 2017). New York: Association for Computing Machinery. https://doi.org/10.1145/3158491.3158504.

Lerdahl, F. (2015). Concepts and representations of musical hierarchy. Music Perception, 33(1), 83-95. https://doi.org/10.1525/mp.2015.33.1.83.

Mor, Y., Dimitriadis, Y., \& Köppe, C. (2020). Workshop: Hybrid learning spaces - data, design, didactics conference (October 2019). Delft, NL.

Ravelli, L. J., \& McMurtrie, R. J. (2017). Networked places as communicative resources. In L. Carvalho, P. Goodyear, \& M. de Laat (Eds.), Place-based spaces for networked learning (pp. 111-130). New York: Routledge.

Schenker, H. (1969). Five graphic music analyses. New York: Dover.

Villasclaras-Fernández, E., Hernández-Leo, D., Asensio-Pérez, J., \& Dimitriadis, Y. (2013). Web Collage: An implementation of support for assessment design in CSCL macro-scripts. Computers \& Education, 67, 79-97. https://doi.org/10.1016/j.compedu.2013.03.002.

Wardak, D. (2016). Inscriptions in educational design meetings. Performance Improvement Quarterly, 29(3), 257-285e. https://doi.org/10.1002/piq.21224. 
Wargo, J. M., Oliveira, G., \& Brownell, C. J. (2021). Sound, sentience, and schooling: Writing the field recording on educational ethnography. Anthropology and Education Quarterly, 52(3), 315-334. https://doi.org/10.1111/aeq.12365.

Wilson, S., \& Zamberlan, L. (2015). Design for an unknown future: Amplified roles for collaboration, new design knowledge, and creativity. Design Issues, 31(2), 3-15. https://doi.org/10.1162/DESI_a_ 00318.

Wilson, S., Huber, E., \& Bryant, P. (forthcoming 2021). Using co-design processes to support strategic pedagogical change in business education. In A. Kjaergaard, A. Lindgreen, E. Rosier, T. U. Thomsen, \& A. Tuncdogan (Eds.), Teaching and Learning in Business Schools. Cheltenham, UK: Edward Elgar. 